\title{
Composição guímica da Cera Epicuticular e CaRacterização da SuPERFÍcie Foliar EM GeNótipos DE CANA-DE-AÇÚCAR ${ }^{1}$
}

\author{
Chemical Composition of Epicuticular Wax and Characterization of Leaf Surface in Sugarcane \\ Genotypes
}

\author{
FERREIRA, E.A. ${ }^{2}$, DEMUNER, A.J. ${ }^{3}$, SILVA, A.A. ${ }^{4}$, SANTOS, J.B. ${ }^{5}$, VENTRELLA, M.C. ${ }^{6}$, \\ MARQUES, A.E. ${ }^{7}$ e PROCÓPIO, S.O. ${ }^{8}$
}

\begin{abstract}
RESUMO - Objetivou-se neste trabalho avaliar a composição química da cera epicuticular e caracterizar a superfície foliar dos cultivares de cana-de-açúcar RB855113 (sensível à mistura de herbicidas trifloxysulfuron-sodium + ametryn), SP80-1842 e SP80-1816, do clone RB957689 (com média sensibilidade à mistura de herbicidas) e do cultivar RB867515 (tolerante). A cera epicuticular foi extraída e quantificada e os seus constituintes analisados por cromatografia a gás, acoplada a espectrômetro de massa (CG-EM). Para determinação da composição química, assim como a caracterização da superfície foliar dos cultivares avaliados, amostras de lâmina foliar foram coletadas e submetidas à microscopia eletrônica de varredura, para caracterização das faces adaxial e abaxial. A análise das amostras revelou a presença de hidrocarbonetos, esteróides, ésteres graxos, álcoois e aldeídos. A cera do cultivar sensivel à mistura (RB855113) apresentou menor número de componentes químicos e predominância de ésteres graxos de cadeia mais curta que os encontrados nos demais cultivares, bem como pequena proporção de esteróides e hidrocarbonetos. Nos cultivares com média sensibilidade (SP80-1842 e RB867515), a cera apresentou maior proporção de hidrocarbonetos e esteróides. A cera do cultivar RB855113 apresentou polaridade intermediária, porém menos polar que a cera do cultivar RB867515 (tolerante à mistura). Não foram observadas diferenças marcantes entre os cultivares no que se refere à micromorfologia foliar.
\end{abstract}

Palavras-chave: composição química, Saccharum spp., micromorfologia foliar e cromatografia a gás.

\begin{abstract}
This study aimed to evaluate the chemical composition of epicuticular wax and to characterize leaf surface in the sugarcane cultivars RB85113 (sensitive to trifloxysulfuron-sodium + ametryn), SP80 1842, SP80 1816, clone RB957689 (with medium sensitivity to trifloxysulfuronsodium + ametryn) and the cultivar RB867515 (tolerant). Epicuticular wax was extracted and quantified, and its contents submitted to gas chromatography coupled to a mass spectrometer. Samples offoliar slides were collected and submitted to electron scanning microscopy to characterize adaxial and abaxial sides, and to determine the chemical composition. This analysis showed the presence of hydrocarbon, steroids, fatty esters, alcohols and aldehyde. The cultivar RB85113 presented wax with lower chemical composition, predominance of fatty esters and low ratio of hydrocarbon. In SP80 1842 and RB867515, the wax presented higher hydrocarbon and steroid ratio. Wax polarity was intermediate in $R B 85113$ but higher in $R B 867515$. In relation to leaf micromorphology, no relevant differences were found.
\end{abstract}

Key words: chemical composition, Saccharum spp., leaf micro-morphology and gas chromatography.

\footnotetext{
Recebido para publicação em 29/3/2005 e na forma revisada em 25/11/2005.

2 Doutorando em Fitotecnia, Dep. de Fitotecnia da Universidade Federal de Viçosa - UFV, 36470-000 Viçosa-MG, <evanderalves@yahoo.com.br>; ${ }^{3}$ Prof. do Dep. de Química da UFV; ${ }^{4}$ Prof. do Dep. de Fitotecnia da UFV; ${ }^{5}$ Pós-Doutor do Dep. de Fitotecnia da UFV; ${ }^{6}$ Prof $^{a}$ do Dep. de Biologia Vegetal da UFV; ${ }^{7}$ Mestranda em Fisiologia Vegetal, Dep. de Biologia Vegetal da UFV; ${ }^{8}$ Prof. da Faculdade de Agronomia da Universidade de Rio Verde - FESURV.
} 


\section{INTRODUÇÃO}

Os herbicidas podem penetrar nas plantas por suas estruturas aéreas (folhas, caules, flores e frutos) e subterrâneas (raízes, rizomas, tubérculos etc.), pelas sementes e, também, durante a germinação e a emergência, pela radícula e pelo caulículo (Silva et al., 2000). Contudo, são as folhas o principal órgão das plantas daninhas envolvido na penetração de herbicidas aplicados em pós-emergência (Procópio et al., 2003). Portanto, o conhecimento dos mecanismos responsáveis pela penetração dos herbicidas em tecidos vegetais pode auxiliar no desenvolvimento de novas técnicas, visando a melhoria da eficiência desses produtos no controle de plantas daninhas.

Em conseqüência da evolução química e biológica dos organismos vivos, desenvolveu-se uma série de estruturas, de natureza polimérica, que os isolam e os protegem das variações do meio ambiente. Essa função é assumida nas plantas superiores pela cutícula ou membrana cuticular (Heredia et al., 1998).

A cutícula cobre as paredes periclinais externas das células epidérmicas, formando um revestimento constituído, principalmente, por substâncias lipídicas. Ela é a principal via de absorção dos herbicidas, o que torna o seu conhecimento de importância fundamental nos estudos de absorção desses compostos (Procópio et al., 2003).

Esse revestimento sobre a parede celulósica primária, do interior para o exterior, é constituído por cutícula secundária ou parede cutinizada (cutícula mais parede), cutícula primária ou cutícula propriamente dita, onde se encontra a cera embebida, e, sobre o revestimento cuticular, na parte mais externa, a cera epicuticular (Heredia et al., 1998).

A composição química do revestimento cuticular é variada, sendo a cutina e a cera seus principais componentes. A cutina é um biopoliéster insolúvel, de elevado grau de entrecruzamento entre os ácidos graxos hidroxilados de cadeia longa que a compõem, enquanto a cera apresenta-se embebida nesse polímero ou depositada no exterior da cutícula (epicuticular). A cera epicuticular pode ser depositada em uma variedade de formas físicas: em algumas plantas, formam camadas finas; em outras, podem formar placas ou cristais de diferentes tamanhos e formas. Devido à sua composição química, refletida no grau de cristalidade, e à possibilidade de constituir na superfície da membrana cuticular uma película que atua como uma interfase entre a célula vegetal e o meio, a cera se destaca como a principal barreira protetora contra as perdas de água por transpiração excessiva, a ação de patógenos, as radiações solares e a entrada de produtos químicos e contaminantes (Heredia et al., 1998).

A quantidade e a composição da cera epicuticular variam com a espécie e com a variedade. As diferenças dependem, também, das condições climáticas, do organismo estudado e da fenologia da planta. A cera epicuticular é uma complexa mistura de diferentes compostos alifáticos. Normalmente, esses compostos contêm séries homólogas de alcanos, álcoois (primários e secundários), aldeídos, ácidos, cetonas, $\beta$-dicetonas, $\beta$ dicetonas e ésteres (Bianchi \& Bianchi, 1990).

Segundo Ahrens (1994), substâncias polares são mais facilmente absorvidas por plantas que apresentam cera epicuticular com composição química mais polar.

Os cultivares e clones de cana-de-açúcar apresentam sensibilidade diferenciada a herbicidas, e a aplicação desses produtos pode promover níveis elevados de fitotoxicidade, ocasionando perdas na produção (Procópio et al., 2003). Esse grau de sensibilidade pode estar associado à morfologia da superfície foliar, bem como à composição química da cera epicuticular.

Este trabalho teve como objetivos caracterizar micromorfologicamente a superfície foliar e determinar a composição química da cera epicuticular dos cultivares de cana-deaçúcar RB855113, RB867515, SP80-1816 e SP80-1842 e do clone RB957689, relacionando tais conhecimentos com o grau de tolerância dos materiais estudados à mistura de herbicidas (trifloxysulfuron-sodium + ametryn).

\section{MATERIAL E MÉTODOS}

O experimento foi realizado na Unidade de Crescimento de Plantas (UCP) do Departamento de Biologia Vegetal da Universidade 
Federal de Viçosa, em ambiente protegido. O ensaio foi conduzido em vasos contendo seis litros de substrato, composto de Argissolo Vermelho-Amarelo adubado, conforme recomendação para a cultura da cana-de-açúcar (CFSEMG, 1999). Em cada vaso foram plantados dois toletes com uma gema cada. O delineamento experimental utilizado foi o de blocos casualizados, com cinco repetições.

Em trabalho anterior, foi verificada a sensibilidade de 15 cultivares de cana-de-açúcar à mistura dos herbicidas trifloxysulfuronsodium + ametryn; desses cultivares, foram selecionados, para estudos anatômicos e químicos, os cultivares RB855113 (sensível à mistura herbicida), SP80-1842 e SP80-1816, o clone RB957689 (medianamente sensivel à mistura) e o cultivar RB867515 (tolerante à mistura). Os dois herbicidas da mistura apresentam estrutura molecular hidrofílica, ou seja, alta polaridade (Ferreira et al., 2005).

As folhas foram coletadas aos 60 dias após a emergência e a cera epicuticular foi extraída da primeira folha com lígula totalmente visivel, utilizando-se a metodologia de Hamilton (1995), com modificações. Para isso, uma folha de cada repetição foi introduzida, separadamente, em placa de Petri com $100 \mathrm{~mL}$ de clorofórmio por 30 segundos, agitando-se levemente. Esse procedimento foi realizado cuidadosamente, para se evitar a ruptura das folhas e a conseqüente liberação dos compostos celulares. Os extratos obtidos foram filtrados com papel-filtro e transferidos para um béquer, onde foram evaporados em banho-maria, até reduzir o volume para, aproximadamente, $15 \mathrm{~mL}$. Esta solução (clorofórmio mais cera) foi transferida para tubos de ensaio de $25 \mathrm{~mL}$, de peso conhecido. O clorofórmio foi evaporado em banhomaria, para obtenção do resíduo sólido (cera). A quantificação da cera foi expressa pela quantidade de cera por unidade de área foliar $\left(\mu \mathrm{g} \mathrm{cm}^{-2}\right)$. Para determinação da área das folhas de cada cultivar, utilizada para extração da cera, foi usado um aparelho fotoelétrico de medição de área foliar ("T Delta-T Devices).

As análises químicas foram feitas no Laboratório de Análise e Síntese de Agroquímicos, pertencente ao Departamento de Química da Universidade Federal de Viçosa. Cada amostra foi submetida à análise em espectrômetro de infravermelho, registrado entre 4.000 e $5.000 \mathrm{~cm}^{-1}$, e transesterificada através de reação com $\mathrm{H}_{2} \mathrm{SO}_{4} /$ metanol. As amostras foram submetidas ao processo de transesterificação para o preparo de seus respectivos ésteres metílicos de ácidos graxos, de acordo com o seguinte procedimento: em cada tubo de ensaio contendo 2 a $5 \mathrm{mg}$, as amostras foram adicionadas em $1 \mathrm{~mL}$ de solução $2 \%$ de $\mathrm{H}_{2} \mathrm{SO}_{4}$ em metanol. Após duas horas em banho-maria, à temperatura de $55^{\circ} \mathrm{C}$, as amostras foram resfriadas à temperatura ambiente. Em seguida, foram adicionados $10 \mathrm{~mL}$ de hexano, e a mistura foi transferida para um funil de separação. A fase orgânica foi separada e lavada com solução saturada de $\mathrm{NaCl}(2 \times 10 \mathrm{~mL})$ e, em seguida, concentrada em evaporador rotatório, dissolvida em $0,2 \mathrm{~mL}$ de hexano e injetada (ìm) em cromatógrafo a gás acoplado ao espectrômetro de massas. Os ésteres metílicos obtidos juntamente com a fração orgânica foram submetidos à cromatografia em fase gasosa acoplada a espectrômetro de massas (CG-EM).

As análises cromatográficas foram realizadas em aparelho GC-MS PQ 5050A (Shimadzu), utilizando-se coluna capilar DB-1 (30 m; 0,25 mm de diâmetro interno; filme de $0,25 \mu \mathrm{m})$ e hélio como gás de arraste. A temperatura do injetor foi de $290{ }^{\circ} \mathrm{C}$, com temperatura inicial de $80{ }^{\circ} \mathrm{C}$, por cinco minutos, aumentando de 80 a $285^{\circ} \mathrm{C}$ na razão de $4{ }^{\circ} \mathrm{C} \mathrm{min}{ }^{-1}$. A temperatura final permaneceu em $285{ }^{\circ} \mathrm{C}$ por 40 minutos. A temperatura do detector foi de $290{ }^{\circ} \mathrm{C}$, e a da interface do sistema CG-EM, de $290^{\circ} \mathrm{C}$. O detector de massas operou com ionização de chama por impacto de elétrons (70 ev) e varredura de massas de 30 a 600 Da. Foi injetado $1 \mu \mathrm{L}$ de cada amostra, e a identificação dos compostos foi feita por meio de comparação dos espectros de massas das amostras com aqueles existentes no banco de dados (Wiley 229.000).

A microscopia eletrônica de varredura foi realizada no Centro de Microscopia e Microanálise (CMMA) da Universidade Federal de Viçosa. Amostras do limbo foliar dos cinco cultivares de cana-de-açúcar foram coletadas para observação em microscopia eletrônica de varredura. Após a coleta, as amostras foram seccionadas em fragmentos de $0,5 \mathrm{~cm}^{2}$ e fixadas em solução de $\mathrm{FAA}_{50}$, por 24 horas a $4{ }^{\circ} \mathrm{C}$. O

Planta Daninha, Viçosa-MG, v. 23, n. 4, p. 611-619, 2005 
material foi desidratado em série etílica progressiva, até etanol absoluto, seco em ponto crítico com $\mathrm{CO}_{2}$ líquido (CPD Bal-tec 030), de acordo com Bozzola \& Russel (1991), e depois fixado em stubs com fita dupla face, onde as amostras foram recobertas com ouro (aproximadamente $20 \mathrm{~nm}$ ), pelo processo de pulverização catódica, em equipamento Balzers de congelamento a seco (modelo FDU 010), acoplado ao conjunto de pulverização catódica (modelo SCA 010). A observação e a documentação fotográfica foram realizadas em microscópio eletrônico de varredura (LEO UP 1430).

Os dados referentes à quantidade de cera epicuticular foram submetidos à análise de variância e ao teste de Tukey a $5 \%$ de probabilidade.

\section{RESULTADOS E DISCUSSÃO}

\section{Composição química da cera epicuticular}

A quantidade de cera epicuticular extraída (Figura 1) foi maior nos cultivares RB867515 $\left(23,22 \mu \mathrm{g} \mathrm{cm}^{-2}\right)$, considerado mais tolerante à mistura de herbicidas, e RB855113 $\left(22,62 \mu \mathrm{g} \mathrm{cm}^{-2}\right)$, sensivel à mistura de herbicidas, diferindo estatisticamente do clone RB957689 $\left(16,39 \mu \mathrm{g} \mathrm{cm}^{-2}\right)$ e do cultivar SP80-1816 (16,26 $\left.\mu \mathrm{g} \mathrm{cm}^{-2}\right)$. Já o cultivar SP80-1842 apresentou quantidade intermediária de cera $\left(20,48 \mu \mathrm{g} \mathrm{cm}^{-2}\right)$. Os valores obtidos em relação à quantidade de cera epicuticular em folhas de cana-de-açúcar estão de acordo com relatos na literatura (Ebercon et al., 1977; McWhorter, 1993).

A cera de cada material avaliado foi submetida à análise espectroscópica na região do infravermelho e caracterizada como uma mistura de ésteres de cadeia longa (Figura 2).

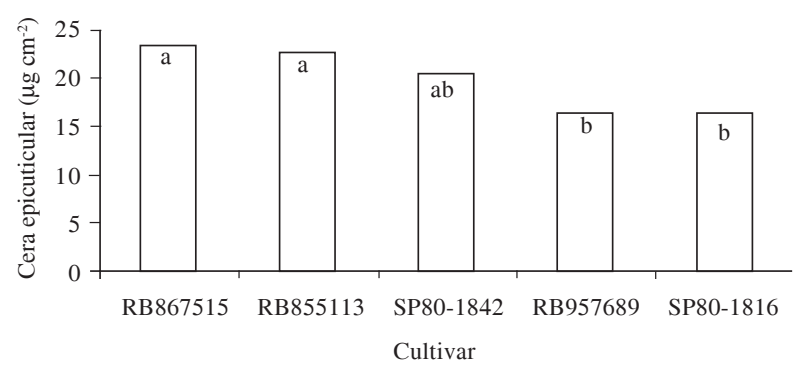

Figura 1 - Cera epicuticular $\left(\mu \mathrm{g} \mathrm{cm}^{-2}\right)$ em cinco cultivares de cana-de-açúcar. Médias seguidas pela mesma letra não diferem entre si pelo teste de Tukey $(\mathrm{P}<0,05)$.

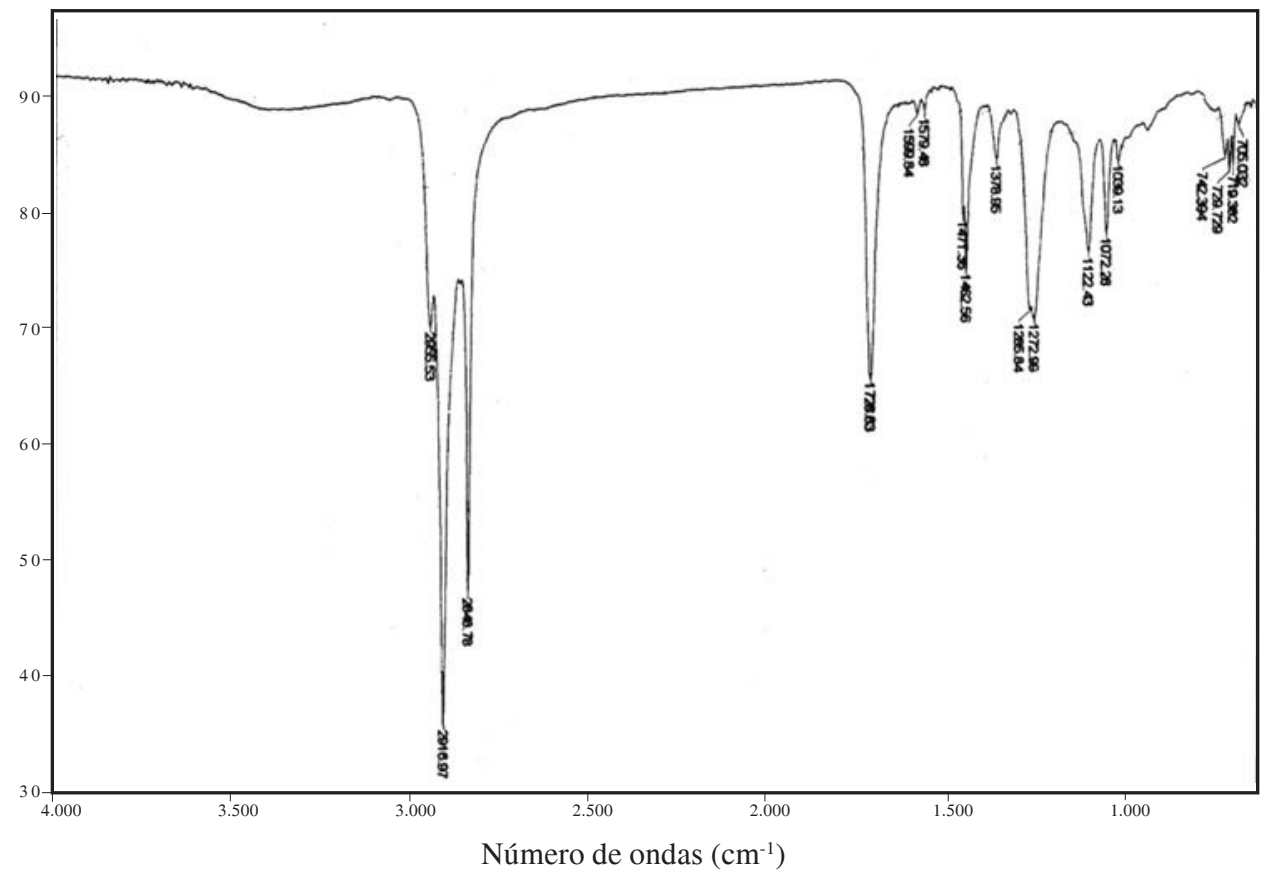

Figura 2 - Espectro no infravermelho $(\mathrm{NaCl})$ da fração da amostra da cera epicuticular do cultivar de cana-de-açúcar RB855113 (mistura de ésteres graxos). 
Essas observações são indicadas pelas bandas em 2.915 e $2.846 \mathrm{~cm}^{-1}$ (deformação de $\mathrm{CH}_{2}$ e $\mathrm{CH}_{3}$ ), $1.726 \mathrm{~cm}^{-1}$ (deformação de $\mathrm{C}=\mathrm{O}$ de éster), 1.225-1.272 $\mathrm{cm}^{-1}$ (deformação de C-O) e $719 \mathrm{~cm}^{-1}$ (deformação de $\left[\mathrm{CH}_{2}\right]_{\mathrm{n}}, \mathrm{n}>4$ ). As misturas de ésteres foram submetidas à reação de transesterificação com $\mathrm{H}_{2} \mathrm{SO}_{4}$ /metanol. Os ésteres metílicos e outros compostos orgânicos presentes na mistura foram identificados por comparação com aqueles contidos na biblioteca do aparelho (Wiley 229.000). Os compostos identificados estão relacionados na Tabela 1 .

Tabela 1 - Composição química (\%) da cera epicuticular das folhas de cinco cultivares de cana-de-açúcar

\begin{tabular}{|c|c|c|c|c|c|c|}
\hline \multirow{2}{*}{$\mathrm{T}_{\mathrm{R}}$} & \multirow{2}{*}{ Composto } & \multicolumn{5}{|c|}{ Cultivar } \\
\hline & & SP80-1842 & RB855113 & RB957689 & RB867515 & SP80-1816 \\
\hline 17,66 & Tetradecano & 6,91 & 4,16 & 2,66 & 3,72 & 2,64 \\
\hline 24,01 & Pentadecano & 1,01 & - & - & - & - \\
\hline 26,45 & $6 E$-Octadecenoato de metila* & $\begin{array}{l}0,74 \\
0,74\end{array}$ & - & 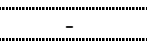 & - & - \\
\hline 27,15 & Tetradecanoato de metila* & 4,95 & - & 1,25 & - n & 0,68 \\
\hline 29,14 & n.i & 2,14 & - & - & - & - \\
\hline 29,39 & Hexadec-1-eno & 3,92 & - & - & - & 0,80 \\
\hline 29,66 & 1-Metilpentadecano & 3,55 & - & - & - & - \\
\hline 29,91 & Pentadecanoato de metila* & 3,18 & 1,65 & "-"'- & - & "'-"'- \\
\hline 31,81 & $9 E$-Hexadecenoato de metila* & 6,59 & 4,37 & - & - & - \\
\hline 32,53 & Hexadecanoato de metila* & 18,23 & 14,83 & 10,54 & 2,51 & 5,11 \\
\hline 34,80 & Hexadecano & 1,77 & 1,67 & -3 & $--m$ & 1,60 \\
\hline 35,05 & n.i & - n & 1,41 & 0,87 & $=$ & -- \\
\hline 36,70 & 9Z-Octadecenoato de metila* & 3,97 & 5,39 & 1,49 & 1,39 & 1,67 \\
\hline 37,45 & Octadecanoato de metila* & 3,89 & 13,52 & 16,91 & 2,23 & 3,39 \\
\hline 39,28 & Tetracosan-1-ol & -- & - & - & 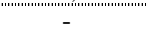 & 1,21 \\
\hline 39,48 & Heptadecano & -"' & - & - & - & 1,97 \\
\hline 41,20 & n.i & $\cdots$ & - & 0,93 & - & 1,61 \\
\hline 41,68 & Icosano & - & - & - & - & 1,25 \\
\hline 41,95 & Icosanoato de metila* & 3,41 & 8,34 & 5,30 & 3,06 & 7,51 \\
\hline 43,17 & Hexanodioato de dimetila* & 5,89 & 17,36 & 1,51 & 4,86 & 8,36 \\
\hline 43,62 & Hexacosan-1-ol & - & - & - & -- & 0,72 \\
\hline 43,81 & Docosano & - & 1,44 & - & - & 1,99 \\
\hline 46,10 & Docosanoato de metila* & 3,88 & 10,30 & 4,50 & 4,04 & 8,07 \\
\hline 46,69 & Tetracosano & -3 & 1,91 & 1,03 & 1,62 & 0,96 \\
\hline 46,79 & Octacosano & - & - & 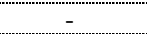 & -- & 1,26 \\
\hline 46,93 & n.i & - & - & - & $-{ }_{-}^{-}$ & 0,80 \\
\hline 49,97 & Tetracosanoato de metila* & 3,37 & 11,48 & 3,79 & 4,65 & 8,70 \\
\hline 52,49 & Esteróide & $-\ldots$ & 2,17 & - & $-\ldots$ & - \\
\hline 53,24 & Hexatriacontano & ")."'- & -- & 0,97 & - & - \\
\hline 53,51 & Triacontanoato de metila* & - & - & 2,19 & - & 2,14 \\
\hline 53,58 & Heptacosanoato de metila* & 1,38 & - & - & 3,76 & - \\
\hline 55,04 & n.i & -- & - & 2,86 & 0,79 & - \\
\hline 55,18 & Esteroide & 2,25 & - & 0,98 & 2,24 & $=$ \\
\hline 55,31 & Octadecanal & -- & - & 1,10 & $--\cdots$ & - \\
\hline 55,33 & n.i & - & $=$ & - & 2,21 & $=$ \\
\hline 55,41 & Esteroide & 2,34 & - & - & -- & - \\
\hline 55,70 & n.i & - & - & 3,52 & 0,98 & $-\cdots$ \\
\hline 55,97 & Esteroide & 5,62 & - & 1,05 & 5,46 & 1,44 \\
\hline 56,60 & Octatriacontano & 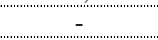 & - & 1,10 & 1,80 & 1,33 \\
\hline 56,65 & Pentatriacontano & 1 & - & - & - & - \\
\hline 56,91 & Heptacosanoato de metila* & $=$ & - & 8,88 & 1,80 & 1,40 \\
\hline 57,31 & Esteroide & 1,15 & - & - & $--\cdots$ & - \\
\hline 58,57 & n.i & 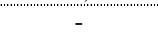 & - & 0,98 & 1,89 & - \\
\hline 58,78 & Esteroide & - & - & - & 10,42 & - \\
\hline 59,34 & n.i & "“"'-" & $=$ & 0,98 & - & - \\
\hline 59,82 & Esteróide & 6,07 & - & 2,36 & - & 12,28 \\
\hline 60,74 & Esteróide & 2,78 & $=$ & 1,18 & 5,20 & 5,06 \\
\hline 61,04 & dotriacontanoato de metila* & $-\ldots$ & - & 3,89 & 10,28 & 1,22 \\
\hline 62,00 & Esteróide & $=$ & $=$ & 0,98 & $-\cdots$ & 1,14 \\
\hline 62,55 & n.i & ")."'- & $=$ & $-=$ & - & 2,97 \\
\hline 63,32 & Esteróide & "'-" & - & 4,89 & 2,58 & 8,04 \\
\hline 63,97 & Hexadecanal & - & - & 0,66 & - & - \\
\hline 64,62 & Esteróide & - & - & 7,82 & 18,60 & 1,34 \\
\hline 66,89 & $2,4,6,8$-tetrametiloctacosanoato de metila* & - & - & 2,80 & 3,90 & 1,34 \\
\hline
\end{tabular}

n.i: não-identificado. $\mathbf{T}_{\mathbf{R}}$ : tempo de retenção. * ésteres graxos. 
Nas amostras submetidas à espectrometria de massas foram encontrados mais de 50 constituintes (Tabela 1). Os grupos de compostos observados na cera epicuticular dos cinco cultivares foram hidrocarbonetos, álcoois, esteróides, ácidos graxos e aldeídos. Os hidrocarbonetos são os componentes menos polares (mais hidrofóbicos) encontrados na cera epicuticular dos cultivares de cana-deaçúcar.

Os componentes tetradecano, hexanoato de metila, 9Z-octadecenoato de metila, octadecanoato de metila, icosanoato de metila, docosanoato de metila e tetracosanoato de metila foram encontrados em todos os cinco cultivares avaliados (Tabela 1).

O componente encontrado em maior proporção no cultivar SP80-1842 foi hexadecanoato de metila $(18,23 \%)$; no cultivar RB855113, hexanodioato de dimetila $(17,36 \%)$ e octadecanoato de metila (16,91\%); no clone RB957689, dotriacontanoato de metila $(10,42 \%)$; um esteróide (10,28\%) no cultivar RB867515; e um esteróide ocorreu em maior proporção no cultivar SP80-1816 (12,28\%) (Tabela 1).

O cultivar RB855113 apresentou, em sua cera, menor variedade de componentes químicos (apenas 15) do que os demais genótipos avaliados. No cultivar SP80-1816 foi observado o maior número de componentes químicos entre os genótipos (31 componentes).

Os ésteres graxos formam o grupo de compostos químicos encontrados em maior proporção na cera epicuticular dos cultivares avaliados. A cera do cultivar RB855113 apresentou maior proporção de ésteres graxos (87,24\%), porém esses ésteres graxos apresentam cadeia mais curta do que os encontrados nos demais genótipos. A quantidade de ésteres graxos encontrados nos demais genótipos foi de $61,62 \%$ no SP80-1842, 63,05\% em RB957689, 42,50\% em RB867515 e 49,52\% em SP80-1816 (Tabela 2).

Os hidrocarbonetos foram encontrados em maior proporção nos cultivares SP80-1842 e RB867515, chegando a 18,16 e 18,06\%, respectivamente, enquanto no clone RB957689 e no cultivar RB855113 a quantidade de hidrocarbonetos foi de 5,76 e 9,18\%, respectivamente. No cultivar SP80-1816, a proporção foi de 13,87\%. Segundo Hamilton (1995), os hidrocarbonetos estão presentes em quase toda a superfície lipídica das plantas, variando quantitativamente de traços até $50 \%$ da quantidade total, mas são predominantes em poucos casos. De acordo com Chachalis et al. (2001), os hidrocarbonetos de cadeia longa são menos polares que álcoois e ésteres. Monquero et al. (2004), trabalhando com as plantas daninhas Commelina benghalensis, Ipomoea grandifolia e Amaranthus hybridus, observaram que C. benghalensis, que possui maior tolerância ao glyphosate, apresentou maior proporção de hidrocarbonetos na cera epicuticular, altamente hidrofóbicos (pouco polares), contrariando a polaridade do glyphosate, que é altamente hidrofílico (Sandberg et al., 1980).

Álcoois e aldeídos foram observados em pequena proporção; cada componente ocorreu em apenas um genótipo. Álcoois foram encontrados em proporção significativa apenas no cultivar SP80-1816, com 1,93\%; os aldeídos, no clone RB957689, com 1,76\%; nos demais genótipos foram observados traços desses componentes.

Na cera epicuticular dos cultivares SP801842, RB867515 e SP80-1816 e do clone RB957689, a proporção de esteróides foi elevada, chegando a 20,20\%, 35,78\%, 29,30\% e $19,26 \%$, respectivamente. O cultivar

Tabela 2 - Grupos de compostos (\%) encontrados na cera epicuticular dos cinco cultivares de cana-de-açúcar avaliados

\begin{tabular}{|c|c|c|c|c|c|}
\hline \multirow{2}{*}{ Composição } & \multicolumn{5}{|c|}{ Cultivares } \\
\hline & SP80-1842 & RB855113 & RB957689 & RB867515 & SP80-1816 \\
\hline Hidrocarbonetos & 18,16 & 9,18 & 5,76 & 18,06 & 13,87 \\
\hline Álcoois & 0 & 0 & 0 & 0 & 1,93 \\
\hline Esteróides & 20,21 & 2,17 & 19,26 & 35,78 & 29,30 \\
\hline Ésteres graxos & 61,62 & 87,24 & 63,05 & 42,50 & 49,52 \\
\hline Aldeídos & 0 & 0 & 1,76 & 0 & 0 \\
\hline NI & 0 & 1,41 & 10,17 & 3,66 & 5,38 \\
\hline
\end{tabular}


RB855113 apresentou apenas 2,17\% de esteróides. Chachalis et al. (2001) afirmam que a proporção de triterpenos (esteróides) pode chegar a $62,00 \%$ em folhas mais jovens, tendendo a cair nas folhas adultas.

Ao avaliar a composição química da cera epicuticular dos cinco cultivares, pode-se estabelecer uma ordem de polaridade. Dessa forma, a cera do cultivar SP80-1816 (média sensibilidade à mistura de herbicidas) foi considerada a mais polar, seguida da cera dos cultivares RB855113 (sensivel) e RB867515 (tolerante), do clone RB957689 (média sensibilidade) e do cultivar SP80-1842 (média sensibilidade), que foi o menos polar.

\section{Caracterização da superfície foliar}

Na face adaxial podem ser observados, em todos os materiais, tricomas espiniformes e
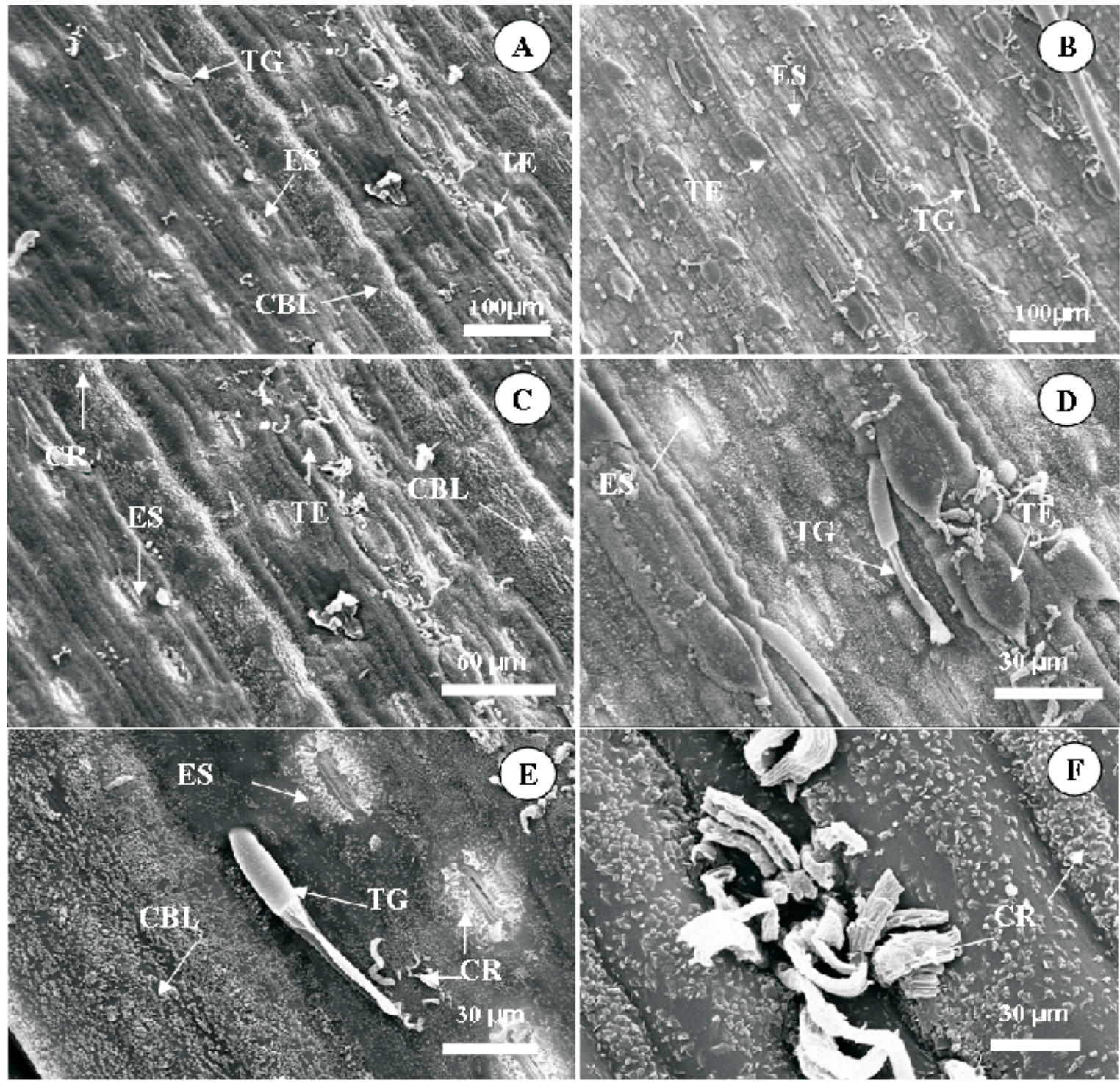

Figura 3 - Superfície foliar dos cultivares de cana-de-açúcar SP80-1842 (A, B, C e D) e RB855113 (E e F). (A) vista geral da face adaxial; (B) vista geral da face abaxial; (C) detalhe de estômatos e células buliformes recobertos por cera na face adaxial; (D) detalhe de tricomas espiniformes e glandulares na face adaxial; (E) detalhe de tricoma glandular, células buliformes e estômatos recobertos por cera na face adaxial; (F) detalhe de cera formando cubos e pequenos grumos na face abaxial. ES: estômatos; CR: cera epicuticular; CBL: células buliformes; TE: tricoma espiniforme; TG: tricoma glandular. 
glandulares (Figura 3A-F). Na face adaxial, os tricomas estão distribuídos em fileiras, alternados com fileiras de estômatos e faixas de células buliformes (Figura 1A,B). Na face abaxial observa-se maior concentração de tricomas do que na face adaxial; esses tricomas estão distribuídos em fileiras alternadas com as fileiras de estômatos, e esse padrão é comum em todos os materiais (Figura 3A, B). Desde 1952, estudos de Van Dillewijn já descreviam a superfície foliar de cana-deaçúcar, onde a epiderme apresenta formações como células buliformes, estômatos do tipo paracítico, células de sílica e tricomas. Astschawager (1925) distinguiu três zonas na epiderme de cana-de-açúcar: 1) uma central, que consiste de células longas alternadas com grupos de células curtas, apresentando tricomas e células de sílica; 2) uma de estômatos; e 3) uma marginal, que consiste de células longas alternadas com células curtas, apresentando também tricomas e células de sílica. Este autor também destacou a importância da face abaxial da epiderme da folha na identificação de variedades cultivadas de cana-de-açúcar, onde se observam características como a distribuição dos tricomas e dos estômatos.

Foi observada cera epicuticular em ambas as faces; a cera está na forma de grânulos muito pequenos, espalhados na superfície foliar e cobrindo todos os tipos de células depositadas principalmente em depressões localizadas na região anticlinal das células da epiderme (Figura 3E, B). Em todos os genótipos pode ser observada a formação de bastonetes de cera (Figura 3F). A cera, em alguns casos, cobre totalmente os estômatos e se deposita sobre os tricomas (Figura 3D, E).

Por meio dessa caracterização química e micromorfológica apresentada, pode-se afirmar que existe diferença apenas na composição química da cera epicuticular entre os cultivares, porém sem relação direta com o grau de sensibilidade à mistura de herbicidas. No cultivar RB855113, mais sensivel à mistura, a cera apresentou polaridade intermediária, e no cultivar RB867515 (tolerante à mistura de herbicidas) foi observada maior polaridade dos componentes da cera em relação ao cultivar mais sensivel. Os cultivares e clones de canade-açúcar não apresentaram diferenças marcantes em sua micromorfologia, sendo todos muito semelhantes. Todavia, os fatores químicos e micromorfológicos devem ser analisados em conjunto com as características anatômicas e fisiológicas.

\section{LITERATURA CITADA}

AHRENS, W. H. Herbicide handbook. 7.ed. Champaign: Weed Science Society of America, 1994. p. 149-152.

ASTSCHAWAGER HEIN, S. A. Anatomy of the vegetative organs of sugarcane. J. Agric., v. 30, p. 197-221, 1925.

BIANCHI, A.; BIANCHI, G. Surface lipid composition of $\mathrm{C}_{3}$ and $\mathrm{C}_{4}$ plants. Biochem. Syst. Ecol., v. 18, p. 533-537, 1990.

BOZZOLA, J. J.; RUSSEL, L. D. Electron microscopy: principles and techniques for biologists. New York: Jones and Bartlett Publishers, 1991. 452 p.

CHACHALIS, C. et al. Characterization of leaf surface,wax composition, and control of redvine and trumpet creeper with glyphosate. Weed Sci., v. 49, p. 156-163, 2001.

COMISSÃO DE FERTILIDADE DO SOLO DO ESTADO DE MINAS GERAIS - CFSEMG. Recomendações para o uso de corretivos e fertilizantes em Minas Gerais - 5 aproximação. Viçosa-MG: Universidade Federal de Viçosa, 1999. 359 p.

EBERCON, A. et al. A rapid colorimetric method for epicuticular wax content of sorghum leaves. Crop Sci., v. 17, p. 179-180, 1977.

FERREIRA, E. A. et al. Sensibilidade de cultivares e clones de cana-de-açúcar à mistura trifloxysulfuron-sodium + ametryn. Planta Daninha, v. 23, n. 1, p. 93-99, 2005.

HAMILTON, R. J. Waxes: chemistry, molecular biology and functions. Edinburgh: Orly Press, 1995. 149 p.

HEREDIA, A. et al. La cutícula vegetal: estructura y funciones. Ecologia, v. 12, p. 293-305, 1998.

McWHORTER, C. G. Epicuticular wax on johnsongrass (Sorgum halepense) leaves. Weed Sci., v. 41, p. 475-482, 1993.

McWHORTER, C. G.; OUZTS, C. Leaf surface morphology of Erythroxylum sp. and droplet spread. Weed Sci., v. 12, p. 293-305, 1993.

MONQUERO, P. A. et al. Caracterização da superficie foliar e das ceras epicuticulares em Commelina benghalesis, Ipomoea grandifolia e Amaranthus hybridus. Planta Daninha, v. 22, p. 203-210, 2004. 
PROCÓPIO, S. O. et al. Anatomia foliar de plantas daninhas do Brasil. Viçosa, MG: Universidade Federal de Viçosa, 2003 a. v. 1.118 p.

PROCÓPIO, S. O. et al. Manejo de plantas daninhas na cultura da cana-de-açúcar. Produção de cana-deaçúcar. Viçosa, MG: Universidade Federal de Viçosa, 2003b. $150 \mathrm{p}$.
SANDBERG, C. L. et al. Absorption, translocation and metabolism of 14C-glyphosate in several weed species. Weed Res., v. 20, p. 195-200, 1980.

SILVA, A. A. et al. Controle de plantas daninhas. Brasília: ABEAS, 2000. 260 p.

VAN DILLEWIJN, C. Botany of sugarcane. Waltham: The Chronica Botanica, 1952. $371 \mathrm{p}$. 